\title{
Early Prediction of Ongoing Hemorrhage in Severe Trauma: Presentation of the Existing Scoring Systems
}

\author{
Martin L Tonglet ${ }^{1, *}$ \\ ${ }^{1}$ Emergency Department, Liege University Hospital, Domaine du Sart Tilman, Belgium \\ "Corresponding author: Martin L Tonglet, Emergency Department, Liege University Hospital, Domaine du Sart Tilman, Belgium, E-mail: tongletm@yahoo.com
}

Received 2015 September 24; Revised 2015 December 03; Accepted 2015 December 06.

\begin{abstract}
Early prediction of ongoing hemorrhage may reduce mortality via the earlier delivery of blood products, adequate orientation of the patient in a dedicated highly specialized and trained infrastructure, and by earlier correction of acute traumatic coagulopathy. We identified 14 scores or algorithms developed for the prediction of ongoing hemorrhage and the need for massive transfusion in severe trauma patients.
\end{abstract}

Keywords: Transfusion, Hemorrhage, Wounds and Injuries

\section{Background}

Early prediction of ongoing hemorrhage and the need for massive transfusion (MT) may reduce mortality via the earlier delivery of blood products, adequate orientation of the patient in a dedicated highly specialized and trained infrastructure, and earlier correction of acute traumatic coagulopathy (ATC). Several scoring systems and algorithms have been developed for this purpose and are presented here.

\section{The Assessment of Blood Consumption Score}

The assessment of blood consumption (ABC) score was initially described in 2009 in a retrospective single-center study of 596 trauma patients. The assessment of blood consumption is based on four un weighted parameters, as follows: 1 , the penetrating mechanism (1 point); 2 , positive focused assessment sonography for trauma (1 point); 3 , arrival systolic blood pressure (SBP) of $90 \mathrm{mmHg}$ or less (1 point), and 4 . arrival heart rate (HR) $\geq 120$ beats per minute bpm (1 point). The score ranges from 0 to 4 , and an $\mathrm{ABC}$ score of 2 or greater was $75 \%$ sensitive and $86 \%$ specific for predicting MT in the study. A re-validation of the $\mathrm{ABC}$ score was published in 2010 with a new retrospective multicenter study including 1,604 trauma patients (1). Adult trauma patients admitted in the resuscitation room with trauma team activation and blood product transfusion during admission from three level 1 trauma centers were included. The assessment of blood consumption was again a reliable score for predicting MT, with a sensitivity of $75 \%-90 \%$, depending on the center, and a specificity of $67 \%-88 \%$.

\section{Emergency Room Transfusion Score}

A first validation of the emergency room transfusion score (ETS) was conducted with a retrospective analysis of severe trauma patients in a German level one trauma center presenting over a period of 4 years (2). A set of six variables with a possible predictive value related to the need for a blood transfusion was recorded and a multivariate logistic regression analysis for correlation was carried out. The ETS includes the following: 1 , blood pressure $(<$ or $>$ $90 \mathrm{mmHg}$ ); 2, free fluid on ultrasound; 3, clinical instability of the pelvic ring; 4 , age (20 - 60 or $>60$ years); 5 , admission from the scene; and 6 , trauma mechanism (traffic accident, fall $>3 \mathrm{~m}$ ). The score ranges from 0 to 9.5 . With a good negative predictive value (NPV; 99.7\%), which was reevaluated in a prospective study (3), an ETS $<3$ indicates a low risk for massive transfusion in the initial phase of care. The positive predictive value (PPV), however, is lower (22.2 $\%$ with ETS $\geq 3$ ).

\section{Prince of Wales Hospital/Rainer Score}

The PWH/Rainer score was developed based on a retrospective analysis of 1,891 trauma patients derived from the PWH trauma registry (4). Seven variables were identified, as follows: 1 , heart rate $\geq 120 \mathrm{bpm}$ (1 point); 2 , SBP $\leq 90$ $\mathrm{mmHg}$ (3 points); 3 , Glasgow coma scale (GCS) $\leq 8$ (1 point); 
4, displaced pelvic fracture (1 point); 5, computed tomography (CT) scan or ultrasound positive for fluid (2 points); 6 , base deficit $>5 \mathrm{mmol} / \mathrm{L}$ (1 point); and 7, hemoglobin (Hb) $\leq 7 \mathrm{~g} / \mathrm{dL}$ (10 points) and Hb 7.1 - $10 \mathrm{~g} / \mathrm{dL1}$ (1 point). The PWH score ranges from 0 to 10 . With a sensitivity of $31.5 \%$ and a specificity of $99.7 \%$, a PWH score $>6$ indicates the need for MT.

\section{Trauma-Associated Severe Hemorrhage Score}

Clinical and laboratory variables documented in the trauma registry of the German Trauma Society (DGU) were subjected to univariate and multivariate logistic regression analysis to predict the probability of MT (5). Seven independent variables were identified and used to build the TASH, as follows: 1 , SBP; 2, Hb; 3, intra-abdominal fluid; 4, complex long bone and/or pelvic fractures; 5, HR; 6, base excess; and 7, gender. The TASH score ranges from 0 to 28. Increasing TASH-score points are associated with increasing probability of MT. A TASH score $\geq 16$ points indicates a probability of MT $>50 \%$. The TASH score has been tested in several studies since its development and is used daily in German trauma centers.

\section{The Traumatic Bleeding Severity Score}

Five predictors of MT were identified in a retrospective analysis of 119 trauma patients and organized to develop the TBSS, as follows: 1 , age; 2 , SBP; 3 , ultrasound (with points attributed for each positive region); 4 , severity of pelvic fracture; and 5, lactate level. The predictive value of the TBSS for MT was then validated using data from 113 severely injured trauma patients. The TBSS is defined as the sum of the component scores and ranges from 0 to 57 points (6). The sensitivity and specificity for a TBSS greater than 15 points were $97.4 \%$ and $96.2 \%$, respectively. The TBSS is simple to calculate using an available iOS application.

\section{The Vandromme Score}

A total of 6,639 patients were included in a retrospective analysis of the registry of a single level one trauma center (7). Admission clinical measurements, including blood lactate of $5 \mathrm{mmol} / \mathrm{L}$ or greater, $\mathrm{HR}>105 \mathrm{bpm}$, international normalized ratio (INR) $>1.5, \mathrm{Hb} 11 \mathrm{~g} / \mathrm{dL}$ or less, and $\mathrm{SBP}<110$ $\mathrm{mmHg}$, were used to create a predictive model. The best-fit predictive model for MT prediction included three or more sensitive measures but it was not possible to build a predictive model using the score.

\section{Code Red}

A recent study was conducted to establish whether the following three simple criteria successfully identified patients in need for massive transfusion on arrival at hospital: 1 , suspicion or evidence of active hemorrhage; 2 , SBP $<$ $90 \mathrm{mmHg}$; and 3, failure of blood pressure to respond to an intravenous fluid bolus (8). Using these three criteria, blood product availability at the receiving hospital was requested. The amount of blood products transfused after admission was recorded. With $91 \%$ of the patients declared Code Red pre-hospital actually receiving blood products transfusion at arrival, Code Red seems to be an interesting tool to activate MT at the receiving hospital, allowing blood products to be made available and potentially facilitating earlier transfusion.

\section{The Shock Index}

The shock index (SI) is defined as HR divided by SBP. It has been demonstrated as a useful guide for diagnosing acute hypovolemia, even in the presence of normal HR or SBP. A recent systematic review of SI capacity for prediction of MT after severe trauma was conducted; this demonstrated an association between higher SI and bleeding. The most frequently suggested optimal SI cut-off value was $\geq$ 0.9 (9). The use of prehospital SI was evaluated in a retrospective study of 8,111 trauma patients with the demonstration of a higher risk for MT with elevation of pre-hospital SI above 0.9 (risk ratio [RR] 1.61, 95\% confidence interval [CI], $1.13-2.31$ for MT when $0.9<$ SI $<1.1$; RR 8.13, 95\% CI, 4.60 14.36 when $\mathrm{SI}>1.3$ ) (10). A patient with an HR of $100 \mathrm{bpm}$ and SBP of $100 \mathrm{mmHg}$ has an SI of 1 and would then be classified as at risk for MT.

\section{The Larson Score}

Developed through a retrospective analysis of combat casualties, the Larson score is a predictive model using four variables, as follows: 1, SBP at the time of admission; 2, HR; 3, $\mathrm{Hb}$; and 4, base deficit (BD) (11). The score ranges from 0 to 4 . In the study, patients presenting with any two of the four variables had a 54\% incidence of MT with a model sensitivity of $69 \%$.

\section{The McLaughlin Score}

Four independent risk factors for MT were identified in a retrospective analysis of 302 combat casualties admitted to a single combat support hospital, constituting the McLaughlin score, as follows: 1, HR > 105 bpm; 2, SBP < 110 
mmHg; 3, $\mathrm{pH}<7.25$; and 4, hematocrit $<32.0 \%$ (12). Those parameters were identified as independent risk factors for MT using univariate and multivariate analysis of the demographic, diagnostic and laboratory variables extracted from the dataset. The score calculation was based on the following complex equation:

Equation 1.

$$
\begin{aligned}
\log \left(\frac{p}{(1-p)}\right)= & 1.576+(0.825 \times S B P)+(0.826 \times H R) \\
& +(1.044 \times H c t)+(0.462 \times p H)
\end{aligned}
$$

It was then tested for an independent dataset of 396 patients with a PPV of $66 \%$, an NPV of $72 \%$, and an area under the receiver operating characteristic curve (AUC) of 0.747 . An un weighted analysis of the four predictive variables was also performed with demonstration of an increasing incidence of MT from $20 \%$ if the patient had one of the values present at arrival to $80 \%$ if all four values were present. However, patients who had none of the four values still had an $11 \%$ incidence of MT.

\section{The Schreiber Score}

The Schreiber scoring system was developed by a retrospective comparison of casualties who required MT to patients who did not. Eight potentially predictive variables were subjected to univariate analysis, and three of them were identified as independently predicting the need for MT, as follows: 1 . $\mathrm{Hb} \leq 11,2$. INR $>1.5$, and 3. penetrating mechanism (13). The single most predictive variable was $\mathrm{Hb} \leq 11 \mathrm{~g} / \mathrm{dL}$, with an odds ratio of 7.7. Using the three variables as a predictive model, the AUC was 0.804 .

\section{Coagulopathy of Severe Trauma Score}

The coagulopathy of severe trauma (COAST) score aims to identify ATC (14). Retrospective data from the Alfred trauma registry were used to identify pre-hospital variables independently associated with coagulopathy. Then, these variables were clinically evaluated to develop a scoring system to predict ATC. The score ranges from 0 to 7 ; points are attributed for entrapment (1 point), body temperature $\left(<35^{\circ} \mathrm{C}: 1\right.$ point, $<32^{\circ} \mathrm{C}: 2$ points), SBP $(<100$ mmHg: 1 point, $<90 \mathrm{mmHg:} 2$ points), abdominal or pelvic content injury (1 point), and chest decompression (1 point). In the prospective validation study on 1,224 trauma patients, a COAST $\geq 3$ had a specificity of $96.4 \%$ with a sensitivity of $60.0 \%$ for ATC with an AUC of 0.83 .

\section{The Trauma-Induced Coagulopathy Clinical Score}

A prospective, non-interventional, single-center study of 82 trauma patients was designed to assess the ability of TICCS to discern patients who need damage control resuscitation (DCR) (15). TICCS ranges from 0 to 18 and is based on the assessment of general severity ( 2 points if the patient is oriented to the resuscitation room as opposed to a regular emergency department room), blood pressure (5 points if SBP $<90 \mathrm{mmHg}$ ), and extent of body injury (1 point for each extremity, 1 point for the head, 2 points for the torso region, 2 points for the abdominal region, and 2 points for the pelvic ring region). TICCS parameters were specifically chosen to be recordable by paramedics in the pre-hospital setting. A cut-off value of 10 provides the best balance between sensitivity (100\%; 95\% CI: 53.9 - 100) and specificity (95.9\%; 95\% CI: 88.2 - 99.2) with a PPV of 72.7\% and an NPV of $100 \%$. Based only on clinical parameters, it can be easily and rapidly measured by paramedics at the trauma site and could help to discriminate between patients with and without the need for DCR.

\section{The Massive Transfusion Score}

Using the entire cohort of the prospective observational multicenter major trauma transfusion (PROMMTT) study, the predictive ability of individual transfusion triggers reported in previous scoring systems was investigated and used to build a new score, the massive transfusion score (MTS) (16). The seven variables are as follows: 1 , INR > 1.5; 2, SBP < $90 \mathrm{mmHg} ; 3, \mathrm{Hb}<11 \mathrm{~g} / \mathrm{dL} ; 4, \mathrm{BD} \geq 6$; 5, positive focused assessment sonography for trauma (FAST); $6, \mathrm{HR} \geq$ $120 \mathrm{bpm}$, and 7. penetrating trauma. MTS thus ranges from 0 to 7 with 1 point attributed for every positive trigger. It was demonstrated that the MTS was sensitive in predicting MT at 24 hours or 6 hours as the number of positive triggers increased. The NPV was 95\%. Thus, patients with less than two positive triggers (MTS $<2$ ) were highly unlikely to receive an MT.

The presented scoring systems were all developed for a same final objective, namely the better prediction of ongoing hemorrhage after severe trauma. However, they were not all designed or evaluated with the exact same methodology, nor with the same context and finality. Three of them were evaluated in the setting of combat casualties. Moreover, 11 were designed to identify patients at risk for MT, generally defined as the use of 10 or more units of packed red blood cells (PRBCs) within the first 24 hours. One (COAST) was specifically designed to predict ATC. One (TICCS) was designed to discern patients with and without a need for DCR (association of MT, immediate surgery, and ATC). Six of them (ABC, ETS, Code Red, SI, COAST, and TICCS) 
Figure 1. The Scoring, Excluding the Code Red and McLaughlin Scores, Which Were Already Described in the Text

\begin{tabular}{|c|c|c|c|}
\hline ABC & ETS & PWH & TASH \\
\hline Criteria & Criteria & Criteria & Criteria \\
\hline Penetrating Mechanism & Age 20 to 60 & SBP $<90 \mathrm{mmHg}$ & $\mathrm{Hb}<7 \mathrm{~g} / \mathrm{dl}$ \\
\hline $\mathrm{SBP}<90 \mathrm{mmHg}$ & Age $>60$ & GCS $<=8$ & $\mathrm{Hb}<9 \mathrm{~g} / \mathrm{dl}$ \\
\hline $\mathrm{HR}>120 \mathrm{bpm}$ & Admission from Scene & $\mathrm{HR}>120 \mathrm{bpm}$ & $\mathrm{Hb}<10 \mathrm{~g} / \mathrm{dl}$ \\
\hline \multirow[t]{10}{*}{ Positive FAST } & Traffic Accident & Displaced Pelvic Fractur & $\mathrm{Hb}<11 \mathrm{~g} / \mathrm{dl}$ \\
\hline & Fall $>3 \mathrm{~m}$ & CT Scan or FAST Positive & $\mathrm{Hb}<12 \mathrm{~g} / \mathrm{dl}$ \\
\hline & SBP from 0 to $90 \mathrm{mmHg}$ & $\mathrm{BD}>5 \mathrm{mM}$ & Base Excess $<10$ \\
\hline & SBP from 90 to $120 \mathrm{mmHg} \quad 1.5$ & $\mathrm{Hb}<=7 \mathrm{~g} / \mathrm{dl}$ & Base Excess $<6$ \\
\hline & Pelvic Ring Disruption & Hb 7 to 10 & Base Excess $<2$ \\
\hline & Abdominal Free Fluid & & $\mathrm{HR}>120 \mathrm{bpm}$ \\
\hline & & & Free Abdominal Fluid \\
\hline & & & Unstable Pelvic Fracture \\
\hline & & & Severe Femur Fracture \\
\hline & & & Male Gender \\
\hline Score Ranges $\quad$ from 0 to 4 & Score Ranges $\quad$ from 0 to 9.5 & Score Ranges $\quad$ from 0 to 10 & Score Ranges $\quad$ from 0 to 28 \\
\hline MT Prediction Threshold 2 & MT Prediction Threshold 4 & MT Prediction Threshold 6 & MT Prediction Threshold 16 \\
\hline Specificity $86 \%$ & & Specificity $97.5 \%$ & \\
\hline Sensitivity $75 \%$ & & Sensitivity $31.5 \%$ & \\
\hline & PPV $22 \%$ & & \\
\hline & NPV 99.7\% & & \\
\hline & & & AUC 0.889 \\
\hline TBSS & Vandromme & Larson & Schreiber \\
\hline Criteria & Criteria & Criteria & Criteria \\
\hline Age $>60$ & $\mathrm{HR}>105 \mathrm{bpm}$ & $\mathrm{HR}>110 \mathrm{bpm}$ & $\mathrm{Hb}<11 \mathrm{~g} / \mathrm{dl}$ \\
\hline Age $<60$ & $\mathrm{SBP}<110 \mathrm{mmHg}$ & $\mathrm{SBP}<110 \mathrm{mmHg}$ & Penetrating Mechanism \\
\hline SBP After 1 L Cryst $>110 \mathrm{mmHg} 0$ & $\mathrm{Hb}<11 \mathrm{~g} / \mathrm{dl}$ & $\mathrm{Hb}<11 \mathrm{~g} / \mathrm{dl}$ & INR $>15$ \\
\hline $100<-<110$ & INR $>1.5$ & Base excess $<6$ & \\
\hline $90 \ll<100$ & Lactate $>=5$ & & \\
\hline$<90$ & & & \\
\hline \multicolumn{4}{|l|}{ FAST $+\quad+3$ for Each Region } \\
\hline \multicolumn{4}{|l|}{ Lactate $<=2.5 \mathrm{~m} \mathrm{M} / \mathrm{l}$} \\
\hline $2.5<-<5$ & & & \\
\hline $5<-<7.5$ & & & \\
\hline$>7.5$ & & & \\
\hline Pelvic Fracture Type A & & & \\
\hline Type B & \multicolumn{3}{|c|}{ Type B } \\
\hline \multicolumn{4}{|l|}{ Type C } \\
\hline Score Ranges $\quad$ from 0 to 57 & Score Ranges & Score Ranges & Score Ranges $\quad$ from 0 to 3 \\
\hline MT Prediction Threshold 15 & MT Prediction Threshold 5 & MT Prediction Threshold 2 & MT Prediction Threshold 3 \\
\hline \multicolumn{4}{|l|}{ Specificity $96.2 \%$} \\
\hline \multirow[t]{2}{*}{ Sensitivity $97.4 \%$} & & Sensitivity $69 \%$ & \\
\hline & & & AUC 0.804 \\
\hline COAST & TICCS & MTS & \\
\hline Criteria & Criteria & Criteria & \\
\hline Entrapment & Going to Resus. Room & INR $>1.5$ & \\
\hline $\mathrm{SBP}<100 \mathrm{mmHg}$ & $\mathrm{SBP}<90 \mathrm{mmHg}$ & $\mathrm{SBP}<90 \mathrm{mmHg}$ & \\
\hline $\mathrm{SBP}<90 \mathrm{mmHg}$ & Head Injury & $\mathrm{Hb}<11 \mathrm{~g} / \mathrm{dl}$ & \\
\hline Temperature $<35 \mathrm{C}$ & Thorax Injury & $\mathrm{BD}>6$ & \\
\hline Temperature $<32 \mathrm{C}$ & Abdominal Injury & $\mathrm{HR}>120 \mathrm{bpm}$ & \\
\hline Chest Decompression & $\begin{array}{l}\text { Pelvic Injury } \\
\end{array}$ & Positive FAST & \\
\hline Abdominal or Pelvic Injury 1 & Injuries to Each 4 Extremities +1 & Penetrating Mechanism & \\
\hline Score Ranges & Score Ranges & Score Ranges & \\
\hline MT Prediction Threshold 3 & MT Prediction Threshold 10 & MT Prediction Threshold $\quad 2$ & \\
\hline Specificity $96.4 \%$ & Specificity $95.9 \%$ & & \\
\hline Sensitivity $60 \%$ & Sensitivity $100 \%$ & & \\
\hline & & NPV 95\% & \\
\hline
\end{tabular}

Abbreviations: AUC, area under the receiver operating characteristic curve; BD, base deficit; FAST, focused assessment sonography for trauma; GCS, Glasgow coma scale; HR, heart rate; Hb, hemoglobin; INR, international normalized ratio; NPV, negative predictive value; MT, massive transfusion; PPV, positive predictive value; SBP, systolic blood pressure.

do not include laboratory results and could be calculable at the trauma site, as long as a pre-hospital physician with competence in ultrasound is in charge. Among these, the Code Red, SI, COAST and TICCS do not include ultrasound and can be calculable at the trauma site by paramedics.
Some of them have been compared to each other in retrospective studies $(17,18)$, showing that sophisticated systems including high number of variables perform better than simple models, and confirming the difficulty of an accurate prediction of ongoing hemorrhage in trauma pa- 
tients. For example, ABC and particularly SI are probably too simple and lack specificity. Their utility in clinical practice and the effect of their use both remain to be further demonstrated. However, many of the scoring systems are used in the clinical setting, such as ABC in most US trauma centers, TASH in most German trauma centers, COAST in Australia, TICCS in our institution and other ones in Belgium, and code red in the London helicopter emergency medical service.

\section{Conclusions}

The prediction of ongoing hemorrhage in severe trauma patients is challenging, and 14 scoring systems or algorithms have been developed to guide clinicians in this critical situation. The evidence of their respective accuracy remains low, as they have mostly been evaluated in retrospective single-center studies. The potential effect of their use on patient outcomes needs to be evaluated, but regardless of the scoring system used, the early identification of trauma patients with ongoing hemorrhage is pivotal for addressing their critical condition. Many of the scores are used in daily clinical practice and seem to be an interesting tool in the management of massive bleeding. The best scoring system would probably be one that combines superior accuracy in predicting the need for MT with an ease of use that would allow early identification of patients requiring MT.

\section{References}

1. Cotton BA, Dossett LA, Haut ER, Shafi S, Nunez TC, Au BK, et al. Multicenter validation of a simplified score to predict massive transfusion in trauma. J Trauma. 2010;69 Suppl 1:S33-9. doi: 10.1097/TA.ob013e3181e42411. [PubMed: 20622617].

2. Ruchholtz S, Pehle B, Lewan U, Lefering R, Muller N, Oberbeck R, et al. The emergency room transfusion score (ETS): prediction of blood transfusion requirement in initial resuscitation after severe trauma. Transfus Med. 2006;16(1):49-56. doi: 10.1111/j.1365-3148.2006.00647.x. [PubMed: 16480439].

3. Kuhne CA, Zettl RP, Fischbacher M, Lefering R, Ruchholtz S. Emergency Transfusion Score (ETS): a useful instrument for prediction of blood transfusion requirement in severely injured patients. World J Surg. 2008;32(6):1183-8. doi: 10.1007/s00268-007-9425-4. [PubMed: 18228093].

4. Rainer TH, Ho AM, Yeung JH, Cheung NK, Wong RS, Tang N, et al. Early risk stratification of patients with major trauma requiring massive blood transfusion. Resuscitation. 2011;82(6):724-9. doi: 10.1016/j.resuscitation.2011.02.016. [PubMed: 21458905].

5. Yucel N, Lefering R, Maegele M, Vorweg M, Tjardes T, Ruchholtz S, et al. Trauma Associated Severe Hemorrhage (TASH)-Score: probability of mass transfusion as surrogate for life threatening hemorrhage after multiple trauma. J Trauma. 2006;60(6):1228-36. doi: 10.1097/01.ta.0000220386.84012.bf. [PubMed: 16766965] discussion 1236-7.

6. Ogura T, Nakamura Y, Nakano M, Izawa Y, Nakamura M, Fujizuka $\mathrm{K}$, et al. Predicting the need for massive transfusion in trauma patients: the Traumatic Bleeding Severity Score. JTrauma Acute Care Surg. 2014;76(5):1243-50. doi: 10.1097/TA.0000000000000200. [PubMed: 24747455].

7. Vandromme MJ, Griffin RL, McGwin GJ, Weinberg JA, Rue L3, Kerby JD. Prospective identification of patients at risk for massive transfusion: an imprecise endeavor. Am Surg. 2011;77(2):155-61. [PubMed: 21337871].

8. Weaver AE, Hunter-Dunn C, Lyon RM, Lockey D, Krogh CL. The effectiveness of a 'Code Red' transfusion request policy initiated by pre-hospital physicians. Injury. 2016;47(1):3-6. doi: 10.1016/j.injury.2015.06.023. [PubMed: 26239421].

9. Olaussen A, Blackburn T, Mitra B, Fitzgerald M. Review article: shock index for prediction of critical bleeding post-trauma: a systematic review. Emerg Med Australas. 2014;26(3):223-8. doi: 10.1111/17426723.12232. [PubMed: 24712642].

10. Vandromme MJ, Griffin RL, Kerby JD, McGwin GJ, Rue L3, Weinberg JA. Identifying risk for massive transfusion in the relatively normotensive patient: utility of the prehospital shock index. J Trauma. 2011;70(2):384-8. doi: 10.1097/TA.0b013e3182095a0a. [PubMed: 21307738] discussion 388-90.

11. Larson CR, White CE, Spinella PC, Jones JA, Holcomb JB, Blackbourne LH, et al. Association of shock, coagulopathy, and initial vital signs with massive transfusion in combat casualties. J Trauma. 2010;69 Suppl 1:S26-32. doi: 10.1097/TA.0b013e3181e423f4. [PubMed: 20622616].

12. McLaughlin DF, Niles SE, Salinas J, Perkins JG, Cox ED, Wade $\mathrm{CE}$, et al. A predictive model for massive transfusion in combat casualty patients. J Trauma. 2008;64(2 Suppl):S57-63. doi: 10.1097/TA.0b013e318160a566. [PubMed: 18376173] discussion S63.

13. Schreiber MA, Perkins J, Kiraly L, Underwood S, Wade C, Holcomb JB. Early predictors of massive transfusion in combat casualties. J Am Coll Surg. 2007;205(4):541-5. doi: 10.1016/j.jamcollsurg.2007.05.007. [PubMed: 17903727].

14. Mitra B, Cameron PA, Mori A, Maini A, Fitzgerald M, Paul E, et al. Early prediction of acute traumatic coagulopathy. Resuscitation. 2011;82(9):1208-13. doi: 10.1016/j.resuscitation.2011.04.007. [PubMed: 21600687].

15. Tonglet ML, Minon JM, Seidel L, Poplavsky JL, Vergnion M. Prehospital identification of trauma patients with early acute coagulopathy and massive bleeding: results of a prospective non-interventional clinical trial evaluating the Trauma Induced Coagulopathy Clinical Score (TICCS). Crit Care. 2014;18(6):648. doi: 10.1186/s13054-014-06480. [PubMed: 25425230].

16. Callcut RA, Cotton BA, Muskat P, Fox EE, Wade CE, Holcomb $\mathrm{JB}$, et al. Defining when to initiate massive transfusion: a validation study of individual massive transfusion triggers in PROMMTT patients. J Trauma Acute Care Surg. 2013;74(1):59-65. doi: 10.1097/TA.0b013e3182788b34. [PubMed: 23271078] discussion 66-7.

17. Mitra B, Rainer TH, Cameron PA. Predicting massive blood transfusion using clinical scores post-trauma. Vox Sang. 2012;102(4):324-30. doi: 10.1111/j.1423-0410.2011.01564.x. [PubMed: 22092220].

18. Brockamp T, Nienaber U, Mutschler M, Wafaisade A, Peiniger S, Lefering $\mathrm{R}$, et al. Predicting on-going hemorrhage and transfusion requirement after severe trauma: a validation of six scoring systems and algorithms on the TraumaRegister DGU. Crit Care. 2012;16(4):R129. doi: 10.1186/cc11432. [PubMed: 22818020]. 